\title{
SOCIO-ECONOIMIC IMPACT OF COVID-19 ON LIVESTOCK
}

\author{
Nasir Iqbal', Zubair Luqman ${ }^{\star 2}$, Hamza Jawad³, Sadaf Aslam¹ and Muhammad Farhab ${ }^{4}$
}

'Department of Veterinary Surgery and Pet Sciences, University of Veterinary and Animal Sciences, Lahore, Pakistan ${ }^{2}$ Department of Anatomy and Histology, Faculty of Veterinary and Animal Sciences, The Islamia University of Bahawalpur, 63100-Pakistan

3Faculty of Veterinary and Animal Sciences, The Islamia University of Bahawalpur, Bahawalpur, Punjab, Pakistan ${ }^{4}$ Department of Pathology, Faculty of Veterinary Science, University of Agriculture Faisalabad, Pakistan

*Corresponding author: drzubairvet@hotmail.com; zubair.luqman@iub.edu.pk

\section{INTRODUCTION}

On $11^{\text {th }}$ of March 2020, World Health Organization (WHO) stated that COVID-19 had become a pandemic disease. In last week of December 2019, the disease started from a report of human beings having pneumonia from an unknown source that was epidemiologically connected to a seafood marketplace in Wuhan city in Hubei Area of China. After research on the causative virus, the disease was named as corona virus disease 2019 (COVID-19). The causative agent is narrative human $\mathrm{CoV}$. It was first named Novel Corona Virus 2019, abbreviated as nCoV2019, then International Committee for the Taxonomy of Viruses, Corona Virus Study Group, named the novel virus as SARS Corona Virus 2 and abbreviated as SARS $\mathrm{CoV}-2$ (Gorbalenya et al. 2020). Corona Virus pandemic disease (COVID-19) is now being considered as a public health disaster for the whole world. The disease, caused by corona virus specifically named as severe acute respiratory syndrome corona virus type 2 (COVID-19), appeared in China on 22 $2^{\text {nd }}$ of December, 2019 and was stated a pandemic by the World Health Organization (WHO) on $11^{\text {th }}$ of March in 2020 due to its global reach. This disease has now been reported in almost 213 counties and territories, with more than 7.8 million definite patients and above 0.49 million humans died internationally.

COVID-19 is transmitted from humans to humans by inhaling aerosol, droplets or through getting in touch with infected surfaces, while its transmission by fecal and oral route is still under consideration. Before this, the world had also seen the appearance of severe acute respiratory syndrome, also called as SARS, outreached in China; and also the outburst of Middle East Respiratory Syndrome (MERS) in the Kingdom Saudi Arabia. These diseases were also caused by Corona virus strains. Corona viruses (CoVs) are divided into four different classifications, named as Alpha-CoV, Beta-CoV, Gamma$\mathrm{CoV}$ and Delta-CoV. Each has its own host, such as humans, swines, dogs, birds, and other animals. To date, there are several human $\mathrm{CoV}$. The alpha-coronaviruses are named as $\mathrm{HCoV}-229 \mathrm{E}$ and $\mathrm{HCoV}-\mathrm{NL} 63$. The $\mathrm{HCoV}-$ $229 \mathrm{E}$ transmits to humans by alpacas and is coming from bats, while $\mathrm{HCoV}-\mathrm{OC}_{43}$ originated from rodents and was transmitted to humans via cattle. The beta-corona viruses are named as SARS-CoV that causes SARS, while MERS-
$\mathrm{CoV}$ that causes MERS and the latest is SARS-CoV-2 that causes COVID-19 (Corman et al. 2014).

\section{Zoonotic Perspective}

The incidence of three extremely pathogenic CoVs outbreaks with a zoonotic origin was recorded in just two decades, enforcing the animal role in creating CoVs with augmented virulence that can acclimatize to human beings, resulting into epidemics and finally pandemic. Thus, the understanding of how zoonotic aspects can affect the human diseases outbreak is important due to the unpredictable nature of these family viruses, evolving and generating strains with different biological properties. This chapter aims to present comprehensive current literature of the three pathogenic CoVs that have already become epidemics and pandemics by showing the structural differences and the zoonotic perspective, such as the animal reservoirs and potential intermediate hosts or the susceptible animals. When the World Health Organization (WHO) has declared COVID-19 as a pandemic disease, it was discussed by all researchers at each level. That's why veterinarians are also considering such pandemics more from Zoonotic point of view to save animals and humans. In the past, MERS and SARS outbreaks affected humans, as well as food, animals. Comparison of SARS, MERS and COVID-19 causative agents structure, their mode of transmission and effects on community are being studied. It is need of time to set policies worldwide to manage the COVID-19 pandemic. By learning from previous outbreaks, some plans must be made and studies should be conducted to overcome this pandemic. The chapter also aims to present and compare the animal reservoirs of these three diseases by collecting information from various sources. With this information, a better understanding about zoonotic aspect of these diseases will be clear. Moreover, better surveillance and vaccine development are expected to be obtained in the near future (Cavanagh 2007; Pedersen 2014).

\section{Source of Transmissions}

A wet and humid environment is most suitable for the survival of this COVID-19 virus. During the outbreak of COVID-19, paper documents, paper money and couriers were also considered as its source of spread, because of its 
highly infectious nature. The virus remains on different inanimate objects from 2 hours to 9 days. It can persist on inanimate objects for up-to 30 days. Transmission risk is low via contacting the contaminated paper, while it is high via respiratory and fecal specimens at room temperature. Poorly ventilated areas increase the chances of virus survival, and absorbent material like cotton have low risk of virus comparative to non-absorbent material used for covering and protection from viral protection (Fletcher et al. 2020).

\section{Deactivation of Virus}

Corona virus (COVID-19/SARS-CoV-2) is ahighly contagious and zoonotic virus. It is transmitted through respiratory droplets, aerosols or contacts. Its frequent route of transmission is touching of infected inanimate public and laboratories surfaces, while due to the highly contagious nature nosocomial infection is also very common. Because of its highly infectious nature, a broad range of disinfectants are used for the inactivation of this virus. In histology and histo-pathological laboratories, a routine tissue processing protocol including the heating of samples in liquid paraffin, inactivates the virus. Use of $80 \%$ ethanol is highly effective for deactivation of the virus. Moreover, tissue preservation in formalin for 24 hours and in glutaraldehyde for $24-48$ hours can also inactivate the virus (Luqman et al. 2020).

\section{Presence of Virus in Raw Water}

There is a vital need to give crystal clear information related to the competence of the water disinfection treatments that is being practiced now-a-days to stop the spread of this virus. The health of workers dealing with hospitals and quarantine centers raw waste water should also be confined by subsequent finest protection practice. This emphasizes the call for the consideration of the possible hazard to developing societies from ecological spread in a different way than those who are provided by sufficient disinfection of raw waste water. It has therefore, been requested to the officials of developing and under developed countries to incorporate safe drinking water supply, leisure water environments, as well as management of raw waste water in the fight against the Corona virus. A final step of disinfection ought to be enforced immediately if existing raw waste water treating centers are not boosted to get rid of viruses like COVID-19 (Wang et al. 2020).

\section{Presence of Virus in Waste}

Since the presence of COVID-19 virus in feces sample has been reported, it has been obvious that this virus is also widespread in human waste water, specifically to the societies near to the hospitals and quarantine centers (Wang et al. 2020). COVID-19 virus has been recognized in sewage water in Australia (Ahmed et al. 2020), Italy (La Rosa et al. 2020); Netherlands (Medem et al. 2020) and France (Wurtzer et al. 2020). The first ever report of
COVID-19 finding in sewage appeared from Netherlands shows its scientific possibility (Medem et al. 2020). A study in some areas of France indicated the continuation of COVID-19 in all type of raw, as well as waste, samples of water and almost 6 out of total 8 treated waste water samples were positive for the virus (Wurtzer et al. 2020). Likewise, almost 6 out of about 12 raw waste water samples coming from the hospitals and quarantine centers in Italy were positive for COVID-19 infection (La Rosa et al. 2020). It has been expected that approximately $5 \%$ of total samples of feces were tested positive for COVID-19 in the testing phase, while the figure of clinically definite cases was about less than $1 \%$. The total number of affected patients in Australia that has been expected from unprocessed waste water was parallel with the clinical observations gained from tested positive patients (Ahmed et al. 2020). On $16^{\text {th }}$ of April 2020, Reuter's news revealed that Government of Australia was by then planning to observe its sewage and raw waste water for the occurrence of COVID-19. A study in the United States depicted those advanced levels of COVID-19 in waste water than what would have been predictable from confirmed clinical cases in different localities (Wo et al. 2020). Studying raw waste water for COVID-19 has, thus been planned as a caution and corresponding move to study the occurrence of COVID-19 infection (Medem et al. 2020; Ahmed et al. 2020; La Rosa et al. 2020, Wo et al. 2020; Wurtzer i 2020). As per report of World Water Development in 2017, it can be depicted that almost $80 \%$ of raw waste water worldwide has been spread in the environment devoid of sufficient treatment. Raw waste water inspection for COVID-19 could offer an impartial chance to find out its epidemiology in different countries that have restricted measures for clinical diagnosis of the disease. Though there is at present no proof of COVID-19 spread by contact to raw waste water coming from aerosols, this spread route was recognized during the severe acute respiratory syndrome occurrence back in 2003 (Hung 2003). Raw waste water aerosols, produced by a faulty raw waste water plumbing organization, were recognized as a possible way of spread the infection inside an accommodation block in the Hong Kong (Hung 2003). The incidence of COVID-19 in raw waste water may, in addition have after effects for human health in the developing countries that are deprived of sewage and water technical disinfection potential, infrastructure, inadequate institutional facilities and low investment for this sudden outbreak. Raw waste water related exposure to COVID-19 remains an important option in such susceptible societies ( $\mathrm{Wu}$ et al. 2020). Similarly, it is an ordinary observation to deposit hospital raw waste water with improper and insufficient action into lakes and canals, which downstream has been utilized for drinking purpose in different areas for human, as well as animals in under developed countries. Cases coming from unintentionally polluted drinking water with unprocessed sewage are common in developing and under developed countries and have also been reported in some developed countries around the globe (Kujansuu et al. 2019). Lastly, the use of raw waste water coming from contaminated 
irrigation water source has the possible effect on the quality of soil and possible boost in crops or the contagion of ground water assets coming from hospitals and quarantine centers by the virus if there.

In the developing countries of the world, a supplementary spread way may be through faecal and oral contact. Theoretically on this phase, the transmission by fecal and oral route has been accounted for spread of many viral diseases like Hepatitis A, Hepatitis E, Hemorrhagic fever and Ebola Virus Disease (Heller 2020). It turns out to be a critical reflection when almost 5 billion people worldwide are lacking right to safely use managed cleanliness, as reported by UNICEF/WHO in 2019. Reserves into raw waste water transportation would also be necessary to add in scheming outbreaks of water borne diseases like Hepatitis. Effective raw waste water disinfection treatment and reduce ecological spread of contaminated raw waste water is also crucial at this stage $(\mathrm{Wu}$ et al. 2020). A major study gap stay alive concerned with the persistence, spread and destiny of COVID-19 in raw waste water coming from hospitals and quarantine centers. Moreover, the environment requires better perception of the ecological persistence, dynamics and transmission of this virus as well. Research is need of the hour to examine relations of the virus with the environment surface and its mode of spread, persistence, and fate in soils, as well as in the aquatic environment, and most importantly in the food chain of under developed and developing countries.

\section{Structure of SARS-CoV-1, MERS-CoV and SARS-CoV-2}

SARS-CoV is an enveloped positive-strand RNA virus, having about $30 \mathrm{~kb}$ nucleotides (Marra 2003). Genome of SARS-CoV-2 also contains positive-strand RNA. SARSCoV-2 can encode a minimum of 4 chief structure proteins, named as envelope protein (E), membrane protein $(\mathrm{M})$, nucleocapsid protein $(\mathrm{N})$ and spike protein (S) $(\mathrm{Wu} 2020)$. S protein, which is type 1 glycoprotein in nature, lies on the exterior of this virus and it first gets in touch with the host cell. Because of its role in receptor binding, $\mathrm{S}$ protein is significant in attachment of virus. Like SARS-CoV and SARS-CoV-2, MERS-CoV also contains four main structural proteins, as have been previously mentioned. Angiotensin-converting enzyme-II (ACE II) is attached to the receptor-binding motif, abbreviated as RBM, in the receptor-binding domain which is denoted as RBD of SARS Corona virus. It serves as a receptor for the virus SARS-CoV (Li et al. 2005; Li et al. 2003). ACE2 is extensively scattered in heart, liver, kidney, testis and intestine. Its basic role is in functions of kidney and heart and also in regulating blood pressure (Anguiano et al. 2017). In recent times, it has been suggested that the entry of SARS-CoV-2 in human cells is promoted by ACE2 (Letko et al. 2020; Zhou et al. 2020). SARS-CoV-2 has receptor-binding domain, known as $\mathrm{RBD}$, which interacts with human ACE2. Therefore, this enzyme is known as the SARS-CoV-2 receptor (Luan et al. 2020). The cellular receptor of both SARS-CoV and SARS$\mathrm{CoV}_{-2}$ is $\mathrm{ACE} 2$, while the MERS-CoV recognizes the dipeptyl peptidase $4\left(\mathrm{DPP}_{4}\right)(\mathrm{Raj} 2013)$.
The Natural Reservoir and Intermediate Host

Wild animals, including bats, are considered natural resources and have an important role in transmitting highly pathogenic viruses, such as Ebola, Coronavirus, and others. Animal markets feared the outbreak of the 2002-2003 SARS-CoV, and are also linked to the sea food and wildlife market for SARS-CoV-2 infections. Wildlife was also thought to be involved in the emergence of SARS-CoV-2. However, it is not confirmed from which species and under what conditions the virus crossed the barrier to infect humans. SARS-COV-2 is the seventh member of the family coronavirus to infect humans, a beta-CoV that has more than $70 \%$ similarity in the genetic sequence of SARS-CoV-2. SARS-COV-2 is more likely to occur in bats, but further confirmation is needed as to whether pneumonia is directly transmitted by SARSCOV-2. Current researches have proved that the novel virus is similar to the bat corona virus throughout the genome level, indicating that bats can be potential hosts of SARS-CoV-2 (Zhou et al. 2020).

Due to their comparable biological characters, SARS-CoV and SARS-CoV-2 are two closely related groups. Moreover, both have animal origin that indicates their ability to infect inter-species. SARS-CoV-2 is evidently from one of the species which are presumed as the zoonotic in origin. This hypothesis is supported by the discovery of several viral sequences that are related to SARS-CoV-2 in several animal species, such as Rhinolopus bats and Malayan pangolins (Manis javanica) (Zhou et al. 2020; Zhang et al. 2020). Nevertheless, the coronavirus of the bat Rhinolophus affinis cannot bind sound to the cellular receptor of humans due to its major difference of the RBD of spike protein in RaTG13, coronavirus in bat (Anderson et al. 2020). On the other hand, the spike protein (S) of SARS-CoV-2, can attach sound to the ACE2 receptors of humans, cats, ferrets and other species with high receptor homology ( $\mathrm{Wu}$ et al. 2020). Some studies have shown that Rhinolophus bats (which include specimen bats in Europe) have coronaviruses closely related viruses found in raccoon dogs (Nyctereutes procyonoides) and masked-palm civets (Pagumalarvata) (Guan et al. 2003; Gouilh et al. 2018). Furthermore, it cannot be concluded that bats are a likely reservoir of MERS-CoV, although MERS-CoV bats were determined to be genetically related to coronaviruses. Some animals, such as the dromedary camels, the alpaca, and the nonhuman primate are susceptible to MERS-CoV. To face the COVID-19 pandemic, WHO has advised people to avoid any contact with wild animals, to process animal products properly, and keep a distance (6 feet distance) with anyone with or without symptoms (Peeri et al. 2020).

$\mathrm{CoV}$ can infect the respiratory tract, gastrointestinal tract, hepatic system and central nervous system of bats, humans, birds, cattle, rodents and various other wild animals (Chen et al. 2020) The origin of severe acute respiratory syndrome corona virus type II is related to bats but the intermediate host has not yet been identified. Due to zoonotic aspects, the susceptibility of ferrets, as 
well as other animals that have close contact with humans, to severe acute respiratory syndrome corona virus type II is very necessary. This virus multiplies poorly in pigs, ducks, chickens and dogs, but cats and ferrets are more vulnerable (Chen and Hualan 2020).

Beside these 2, cats also tested positive for SARS-CoV-2, with mild clinical signs in New York in late April, as reported by the United states Department of Agriculture and Federal Centers for Disease Control and Prevention. The diseases were transmitted by mildly ill or asymptomatic contacts or household members that might have COVID-19. Therefore, USDA recommends routine testing of animals, as the occurrence is rare (CDC, 2020; Almendros 2020).

\section{Virus in Laboratory Animals}

Macacamullata has limited utility to become SARS-CoV animal model in showing SARS pathogenesis and the evaluation of therapies. Because of its high titer in the air tract of mice and findings in mice after SARS-CoV inoculation, it makes mice a good choice to be the animal model for the vaccine, antiviral and immune prophylaxis researches ( $\mathrm{Du}$ et al. 2009). The mice also can be the animal model of SARS pathogenesis. Hamsters also can be the ideal animal model because of the high titer in the respiratory tract, while other susceptible animals are ferrets, macaques and African green monkeys. Squirrel monkeys and mustached tamarin are not susceptible to SARS-CoV (Subbarao et al. 2006). The macaquesis are one of the MERS-CoV susceptible animals. Therefore, the macaques can be the suitable model for the study of MERS-CoV pathogenesis and vaccine development. However, ferrets, mice and hamsters are not infected by MERS-CoV. The dromedary camel and alpaca can be the animal model because of their susceptibility. Based on Jianzhong Shi's research, ferrets and cats show high susceptibility. The dogs have low susceptibility and the livestock such as pigs, chicken, and ducks are not susceptible to the infection (Shi et al. 2020).

\section{Effects of Coronavirus on Global Food System}

Coronavirus disease (COVID-19) has adversely affected the current food system globally. Like the health system, the stability of the food system should be a priority during a lockdown. The pandemic severely affects food safety and security. The livestock sector is a major source of animal food products. The economics of the processed milk and meat industries are being severely affected during the lockdown. Due to the lack of transportation facilities, livestock products are not available to everyone. The importance of incorporating new technologies into the livestock sector to lessen the undesirable effects of the global epidemic on the animal-based food industry cannot be over-looked. Animal production and disease resistance must be improved through breeding and genetics. The role of veterinarians in maintaining animal health and preventing zoonotic diseases during infectious diseases outbreaks should also be highlighted.
Implementation of new policies in the livestock sector regarding the telemedicine, online sale and purchase of animals and their products is necessary. Such guidelines could help the state to overcome crises related to food, livestock and human health. Countries around the world have policies to prevent the spread of the pandemic, such as lockdowns, inter-regional traffic restrictions, prohibition of various activities involving gatherings and large-scale COVID-19 testing (Tesso 2020). Government has also established a community health emergency in the framework of accelerating the handling of COVID-19 through Presidential Decree No. 11 of 2020 and Government Regulation No. 21 of 2020 (Djalante et al. 2020). The pandemic not only has a negative impact on the health sector but also threatens various sectors, such as the food, economy, society, education and many others (Viner et al. 2020). Faced with the current situation, scientists and stakeholders have predicted that the current pandemic will have both short and long-term effects. Livestock is an important sector for preparation. The sector that is predicted to attain the Sustainable Development Goals (SDGs) in 2030 cannot escape the negative effects of this global crisis (Rasul 2016). Not only the impacts mentioned earlier, but also the lack of animal-derived food, is one of the challenges and risks of the current COVID-19 pandemic and post-pandemic rehabilitation period (Galanakis 2020). Numerous fields related to animal-based food supplementation have been suspended during the pandemic, so that production processes, distribution and consumption are not functioning normally (Thornton 2010; Deaton and Brady 2020).

\section{Importance of Livestock Sector during Pandemics}

Food security is primary task of every state; and like agriculture sector, livestock sector also has great importance in providing food to us all. The importance of agro-industrial complex can never be ignored, especially during pandemics. Balance between food sources and population requirements is necessary to provide sufficient food supplies during current COVID-19 lockdown situations (Monchatre 2017). As urbanization is increasing, the consumption of livestock products is also increasing continually. Farming and processing units are present only in big cities but not in every city. People of many cities face great shortage of livestock products, like milk and meat, during pandemics and lockdowns (Grace et al. 2020; Mhlanga and Emmanuel 2020).

Numerous fields related to animal-based food supplementation have been suspended during the pandemic, so that production processes, distribution and consumption are not functioning normally (Thornton 2010, Henchion 2017). In addition to the effects of COVID19, the ability to produce many animal-derived products that have not yet met the requirements, the risk factor for antibiotic resistance in meat and milk, causes a shortage of food for humans. According to One Health concept, animal health is very important for keeping human healthy (Boland et al. 2013; Osterhaus et al. 2020). 


\section{Optimization of Animal Products during Pandemics}

The data related to previous scientific studies about veterinary hygiene and veterinary medicine can help a lot in optimizing the supply of livestock products. By such scientific data, we want the minimum cost of livestock products by optimum parameters of the climate and maintain production mechanisms up to the optimum level (Bishwajit et al. 2014). In-ovo feeding of Larginine amino acid increased the meat quality and final weight of birds (Luqman et al. 2020). Effective solutions of systems during pandemics save time, money and provide food sources to everyone (Dalvit and Cassandro 2007). Technology is the most needed tool to optimize production of animals, their feed consumption, and environmental system of animal farms and livestock products (Samarin et al. 2018).

\section{Improved Genetics and Modern Breeding Technologies}

Modern breeding technologies can improve genetic potential of food animals, and animal products can be increased by these procedures. Current pandemic has shed light on importance of such advances in all livestock fields (Xu et al. 2020) An effective breeding strategy in food animals is one of the ways in which cattle breeders can be successful. In many under developed countries, cattle selection is usually traditionally performed with phenotypic observations. This choice is less efficient. This is evidenced by the self-sufficiency of meat, which has not been announced since 2010. The mapping of Quantitative Treat Loci - encoding the quantitative role of genetic loci in food animals - is expected to provide a more accurate selection process. Animal selection through genome selection begins with an understanding of genome mapping. Genome mapping is used to identify the location of genes, locus on chromosomes and mutations (Xiong 2006). Quantitative Trait Loci or QTL is the locus that is mapped. Many of these characteristics are important, both economically and medically, such as resistance to diseases, meat and milk production. The basic concept in genomic selection is that single nucleotide polymorphisms (SNPs) are considered as a marker of the relationship between loci. Next, identification or marking of SNPs can be done by identifying QTL locations in the genome for genetic mapping of species (Mrode et al. 2019). However, some simple markers can be used to understand the advantages and disadvantages of these markers. The precision of genomic selection depends on the distance of the marker with QTL, the process identification of phenotype, and the number of genes to be identified (Semagn 2006). Inovo technique can meet the embryonic requirement during the incubation period by increasing the viability of embryo (Luqman et al. 2019).

The Flow of Genetic Mapping Can Easily be Described as:
- To use SNPs as markers, the genome needs to be read using microarrays. Unfortunately, the use of micro-arrays is less common in underdeveloped countries than the use of electrophoresis.

- Using a marker other than SNP would mean an easier flow, namely: DNA extraction - amplification of DNA by utilization of PCR (polymerase chain reaction), electrophoresis using markers, Readout of results (Gutiérrez-Gil et al. 2007).

- Due to the limited supply of feed, animal feed management also needs to be improved to deal with food safety. Safe production of animal feed is one of the most important methods for the health and management of livestock. Genome mapping can also be done in animal feed plants. Selection through this genome can improve the accuracy of phenotypic selection, which has been done extensively in Pakistan. Several parties involved in the development of the livestock sector in Pakistan have been able to work together to obtain selective livestock genomes through the collection of integrated livestock genome data (Xiong 2006).

\section{Branding and Digitalization of Livestock Products to} Overcome Sales Decline

A previous study has shown that consumers between the ages of 15 and 25 years buy food and ingredients prepared during pandemics online (Kirtiş and Filiz 2011). This can be done through various platforms and communities that are formed on social media. Promotion through media can be done by many people with a large number of followers or paid promotion on accounts with access to large media (Salomonsson 2003). Promotional material in the form of a campaign to use nutritious livestock products during the current pandemic can be an interesting selling point. Processed food made from livestock products or local culinary products can be sold by this tricky way (Heath 2018).

The second step is delivery services, which are very important in this situation. Delivery services can be made through form employee courier or using campaign services, or it can also use e-commerce which provides delivery services and even free shipping coupons (Pueyo 2020).

Easy access to product information, payment and product delivery can help propel the market forward to keep the business going during the lockdown. Small-scale farms can encourage each other through collaboration to maximize their impact on improving livestock product development methods and marketing processes. It is expected that these two solutions will solve the problem of low market for livestock products and help in distribution of livestock products (Shaner 2019).

Processing Techniques and Marketing Facilities for Animal Products 
Improving the processing techniques and marketing facilities of animal products by increasing their distribution facilities and increasing the marketing force are necessary steps to prevent food shortage during lockdown and pandemics (Galanakis 2020). If a lockdown lasts longer, then people will need animal products and by-products that are long-term stable, durable and have quality packaging (Khan et al. 2020). Processed livestock products like meat, which has high nutritional and water level, is the right medium for growing micro-organisms, thus making it easier to rot the meat. Therefore, proper processing of such products is much necessary. Because the meat might have to be stored for longer durations in stores or at homes in lockdown situations through freezing, the meat is cooked with selected herbs and then packaged and frozen. Freezing techniques are also used mostly in indoor areas (Rahman 1999). In addition, thermal processing and smoking products are used in other scales to avoid the damage caused by decaying conditions. Processing techniques, flavoring skills and preservation techniques are key to improving the quality of livestock products (Robinson et al. 2002; Chelule et al. 2010). The creative ability to make coffee flavor with milk can be an attractive product to increase sales during such pandemics. Some other preparations for milk processing, such as doodle milk, may be other options (Dixon et al. 2001).

\section{Telehealth Facility}

This situation is causing difficulties and delay in providing treatment to animals. However, this problem can be solved by using telehealth facility. Barriers in the use of telehealth at each community level should be solved at the earliest. Cases other than emergency situation can be tackled easily from the farm. In this way, animals can remain safe and food resources will not decline. Government should prepare telehealth doctors force for livestock, and related courses should be included in curriculum of veterinary education. Telehealth is safe for doctors and it will also decrease the stress for farmers and their families (Zhou et al. 2020).

\section{The Future of Animal Farming}

The complexity of these food issues requires a multifaceted and appropriate strategy for mutual cooperation, so that we can fight malnutrition during COVID-19 epidemics. After recovering from the current pandemic, we must be better prepared for the future crisis (Galli et al. 2020; Holmes et al. 2020) The malnutrition warning alarm starts when one-third of the world's population experiences limited mobility (Galanakis 2020). The pandemic of COVID-19 will definitely reduce the attention of different countries on livestock health and production. The Food and Agriculture Organization (FAO) recommends that countries pay special attention to food and develop strategies to deal with it in order to create food safety during coronavirus emergencies. The long-term measures are needed to be taken seriously. The livestock sector also supports success in meeting food security (Rosegrant and Sarah 2003). To improve the health of food animals, especially during pandemics and during communicable health issues, telehealth technologies should be utilized proactively in livestock sector. During the current coronavirus pandemic lockdown, farmers are also facing transport issues (Malhotra 2020).

It is responsibility of political leaders and educational institutes to make necessary policies regarding food resources management for the whole nation during pandemics (Moon et al. 2015) One can't say anything about the occurrence of such pandemics in future. Because epidemics and pandemics are occurring from hundreds of years and we can't say anything even about COVID-19 reoccurrence in future (Sun et al. 2020). But we can prepare public for such future crisis by improving our health facilities, especially those related to food animals. Since theCOVID-19 also has some origin from wet food market, direct involvement of animal health should be the first concern (Yang et al. 2020).

\section{Covid-19 Vaccination Preparation and Use of Animals}

Till new advance in developing vaccines against pandemic causing viruses, scientists are using laboratory animals for vaccination trials (Ahmed et al. 2020) Therefore, new policies and guidelines are very necessary for laboratory or experimental animal health and production management. Industry and government co-ordination can solve such problems by collaborating with academic institutes (Malhotra 2020).

\section{Role of Veterinarians in Meat Markets}

Meat markets, where animals are of different kinds (wild and domestic) are sold, are a main source of origin of zoonotic disease. Many researchers have suggested that bats are reservoir hosts for many coronaviruses, but they are asymptomatic to coronaviruses (Daszak et al. 2020; Tiwari et al. 2020). The SARS-CoV-2 was also transmitted between different species in wet markets in Wuhan city, China. Therefore, these markets should be considered by veterinarians from a zoonotic point of view (Leach and Ian 2013). Such markets cannot be banned but can be regulated by new rules and regulations. It is now imperative to reduce the likelihood of this pandemic occurring in the future through a collaborative process between veterinarians, doctors and environmental scientists, nationally and internationally. Because there is a direct relationship between humans, animals and their common environment, therefore, it is important for everyone's health to protect themselves from future outbreaks and pandemics, such as from SARS, MERS and COVID-19 like pandemics (Almendros 2020).

\section{Conclusion}

Based on the above explanation, the effects of COVID-19 have affected the livestock sector. This is evidenced by the 
poor condition of the livestock market. In addition, the risk of future malnutrition and food shortage is also predicted. To solve these issues farmers should increase the immunity of their domestic animals by adding micronutrients to their rations. It is important to avoid feed shortages in the future, especially during pandemics. Healthy eating and drinking food animals are a source of healthy meat and milk. Animal food shortages can be overcome by improving the genetics of animals and animal feed plants and incorporating unconventional feed resources into their diets. Tele-health or telemedicine facilities should be improved to provide proper treatment to the farmers in case of any kind of lockdown. Increase the number of meat and milk processing plants in all cities to provide permanent fresh food to the people during any future crisis. Increasing the value addition of livestock products can ensure an increase in income. Digitization in the livestock business will make it easier, faster and safer to sell and buy livestock products. This will be especially helpful during infectious and contagious diseases. Online buying and selling, such as the use of information technology and computer science, can create new markets for livestock products and services by implementing the COVID-19 security protocol. Farm biosafety and biosecurity are essential to prevent infectious and zoonotic diseases. These suggestions can help academic researchers, food sector scientist and livestock sector to reduce losses and waste of food. New research is needed to identify alternative safe sources of protein that can meet all kinds of nutritional needs of people in under-developed countries like Pakistan.

\section{REFERENCES}

Ahmed SF, et al., 2020. Preliminary identification of potential vaccine targets for the COVID-19 coronavirus (SARS-CoV-2) based on SARS-CoV immunological studies. Viruses 12: 254.

Ahmed W, et al., 2020. First confirmed detection of SARS-CoV- 2 in untreated wastewater in Australia: A proof of concept for the wastewater surveillance of COVID-19 in the community. Science of the Total Environment 728: 138764 .

Angel A, 2020. Can companion animals become infected with Covid-19? Veterinary Record 186: 388-389.

Angel A, 2020. Can pets transmit COVID-19 infection? Open Veterinary Journal 2020: 1-3.

Anderson RM, et al., 2020. How will country-based mitigation measures influence the course of the COVID-19 epidemic? The Lancet 395: 931-934.

Anguiano L, et al., 2017. Circulating ACE2 in cardiovascular and kidney diseases. Current Medicinal Chemistry 24: 3231-3241.

Anguiano M, et al., 2017. Characterization of threedimensional cancer cell migration in mixed collagenMatrigel scaffolds using microfluidics and image analysis. PloS One 12: eo171417.

Ghose B, et al., 2014 Trade liberalization, urbanization and nutrition transition in Asian countries. Journal of Nutrition and Food Sciences 2: 5.
Boland Mike J, et al., 2013. The future supply of animalderived protein for human consumption. Trends in Food Science \& Technology 29: 62-73.

Cavanagh D, 2007. Coronavirus avian infectious bronchitis virus. Veterinary Research 38: 281-297.

Chelule PK, et al., 2010. Advantages of traditional lactic acid bacteria fermentation of food in Africa. Current Research, Technology and Education Topics in Applied Microbiology and Microbial Biotechnology 2: 1160-1167.

Chen ad Hualan, 2020. Susceptibility of ferrets, cats, dogs, and different domestic animals to SARS-coronavirus2. Science 368: 1016-1020.

Yu C, et al., 2020. Emerging coronaviruses: Genome structure, replication, and pathogenesis. Journal of Medical Virology 92: 418-423.

Corman VM, et al., 2014. Characterization of a novel betacoronavirus related to middle East respiratory syndrome coronavirus in European hedgehogs. Journal of Virology 88: 717-724.

Dalvit C, et al., 2007. Genetic traceability of livestock products: A review. Meat Science 77: 437-449.

Peter D, et al., 2020. A strategy to prevent future epidemics similar to the $2019-\mathrm{nCoV}$ outbreak. Biosafety and Health 2: 6-8.

Deaton BJ, et al., 2020. Food security and Canada's agricultural system challenged by COVID-19. Canadian Journal of Agricultural Economics/Revue Canadienne d'agroeconomie 68: 143-149.

Dixon John A et al., 2001. Farming systems and poverty: Improving farmers' livelihoods in a changing world. Food \& Agriculture Organization 2020: 1-49.

Riyanti D, et al., 2020. Review and analysis of current responses to COVID-19 in Indonesia: Period of January to March 2020. Progress in Disaster Science 100091. Progress in Disaster Science 6: April 2020.

$\mathrm{Du} \mathrm{Y}$ et al., 2009. Oxidative damage to the promoter region of $\mathrm{SQSTM}_{1} / \mathrm{p} 62$ is common to neurodegenerative disease. Neurobiology of Disease 35: 302-310.

Fletcher R, et al., 2020. News media broadly trusted as source of coronavirus information, views of UK government response highly polarised. Reuters Institute.

Galanakis et al., 2020. The food systems in the era of the coronavirus (COVID-19) pandemic crisis. Foods 9: 523.

Francesco G, et al., 2020. Better prepare for the next one. Lifestyle lessons from the COVID-19 pandemic. Pharma Nutrition 12: 100193.

Gorbalenya A, et al., 2020. Coronaviridae Study Group of the International Committee on Taxonomy of Viruses. The species severe acute respiratory syndrome-related coronavirus: Classifying 2019-nCoV and naming it SARS-CoV-2. Nature Microbiology 2020: 03-04.

Gouilh MA, et al., 2018. SARS-CoV related Betacoronavirus and diverse Alphacoronavirus members found in western old-world. Virology 517: 88-97. 
Delia G, et al., 2020. Optimizing livestock farming in urban agriculture. Burleigh Dodds Science Publishing. Cambridge, UK.

Guan Y, et al., 2003. Isolation and characterization of viruses related to the SARS coronavirus from animals in southern China. Science 302: 276-278.

Beatriz GG, et al., 2007. Genetic effects on coat colour in cattle: Dilution of eumelanin and phaeomelanin pigments in an $\mathrm{F}_{2}$-backcross Charolais $\times$ Holstein population. BMC Genetics 8: 56.

Stephan H, 2018. Mobile device system and method providing combined delivery system using $3 \mathrm{D}$ geotarget location-based mobile commerce searching/ purchases, discounts/coupons products, goods, and services, or service providers-geomapping-company/ local and socially-conscious information/social networking ("PS-GM-C/LandSC/I-SN"). U.S. Patent No. 10,140,620. 27 Nov. 2018.

Heller L, et al., 2020. COVID-19 faecal-oral transmission: Are we asking the right questions? Science of the Total Environment 729: 138919.

Maeve H, et al., 2017. Future protein supply and demand: Strategies and factors influencing a sustainable equilibrium. Foods 6: 53.

Holmes Emily A, et al., 2020. Multidisciplinary research priorities for the COVID-19 pandemic: A call for action for mental health science. The Lancet Psychiatry 7: 547-56o.

Hung LS, 2003. The SARS epidemic in Hong Kong: What lessons have we learned? Journal of the Royal Society of Medicine 96: 374-378.

Jensen Robert $\mathrm{T}$ et al., 2011. Do consumer price subsidies really improve nutrition?. Review of Economics and Statistics 93: 1205-1223.

Jin $\mathrm{YH}$, et al., 2020. A rapid advice guideline for the diagnosis and treatment of 2019 novel coronavirus (2019-nCoV) infected pneumonia (standard version). Military Medical Research 7: 4 .

Romdhane K, et al., 2007. A review of the analytical methods coupled with chemometric tools for the determination of the quality and identity of dairy products. Food Chemistry 102: 621-640.

Naushad K, et al., 2020. COVID-2019 locked down impact on dairy industry in the world. Available at SSRN 3616325 .

Kirtiş A, et al., 2011. To be or not to be in social media arena as the most cost-efficient marketing strategy after the global recession. Procedia-Social and Behavioral Sciences 24: 260-268.

Kujansuu E, et al., 2019. Exposure to sewage water and the development of allergic manifestations in Finnish children. Pediatric Allergy and Immunology 30: 598603.

La Rosa G, et al., 2020. First detection of COVID-19 in untreated wastewaters in Italy. Science of the Total Environment 736: 139652.

Melissa L et al., 2013. The social and political lives of zoonotic disease models: Narratives, science and policy. Social Science \& Medicine 88: 10-17.

Letko M, et al., 2020. Functional assessment of cell entry and receptor usage for SARS-CoV-2 and other lineage $B$ betacoronaviruses. Nature Microbiology 5:562-569.

Li F, et al., 2005. Structure of SARS coronavirus spike receptor-binding domain complexed with receptor. Science 309: 1864-1868.

$\mathrm{Li} \mathrm{W}$, et al., 2003. Angiotensin-converting enzyme 2 is a functional receptor for the SARS coronavirus. Nature 426: $450-454$.

Luan J, et al., 2020. Spike protein recognition of mammalian $\mathrm{ACE} 2$ predicts the host range and an optimized ACE2 for SARS-CoV-2 infection. Biochemical and Biophysical Research Communications 526: 165-169.

Luan J, et al., 2020. Spike protein recognition of mammalian $\mathrm{ACE}_{2}$ predicts the host range and an optimized $\mathrm{ACE}_{2}$ for SARS-CoV-2 infection. Biochemical and Biophysical Research Communications. Biochemical and biophysical research communications 526: 165-169.

Luqman Z, et al., 2019. Effect of in ovo inoculation on productive performances and histo-physiological traits in commercial birds. International Journal of Scientific and Engineering Research 10: 1664-1673.

Luqman Z, et al., 2020. Disinfection of corona virus in histopathology laboratories. Clinical Anatomy 33: 975-976.

Luqman Z, et al., 2020. Effect of in-ovo administration of L-arginine on the gross anatomy of tibia bone, alkaline phospahtase and growth performance in Japanese quail (Coturnix japonica). Journal of Animal Health and Production 9: 22-26.

Luqman Z, et al., 2020. In-ovo effects of lysine amino acid on the histomorphometry of thigh muscles, cecal tonsils and $\mathrm{pH}$ in Japanese quail. Pak Euro Journal of Medical \& Life Science 3: 1-5.

Malhotra D, 2020. managing agricultural supply chains in COVID-19 lockdown. Available at SSRN 3602574.

Malhotra N, et al., 2020. Indian society of anaesthesiologists (ISA national) advisory and position statement regarding COVID-19. Indian Journal of Anaesthesia 64: 259.

Marra MA, et al., 2003. The genome sequence of the SARS-associated coronavirus. Science 300: 1399-1404.

Melin Amanda D, et al., 2020. Comparative ACE2 variation and primate COVID-19 risk. Bio Rxiv 2020: 1-9.

David M et al., 2020. Socio-economic implications of the COVID-19 pandemic on smallholder livelihoods in Zimbabwe. Preprints 2020, 2020040219.

Monchatre-Leroy et al., 2017. Spatial and temporal epidemiology of Nephropathia epidemica incidence and hantavirus seroprevalence in rodent hosts: Identification of the main environmental factors in Europe. Transboundary and Emerging Diseases 64: 1210-1228.

Suerie M, et al., 2015. Will Ebola change the game? Ten essential reforms before the next pandemic. The report of the Harvard-LSHTM Independent Panel on the Global Response to Ebola. The Lancet 2015: 22042221. 
Mrode R, et al., 2019. Genomic selection and use of molecular tools in breeding programs for indigenous and crossbred cattle in developing countries: Current status and future prospects. Frontiers in Genetics 9: 694.

Osterhaus Albert DME, et al., 2020. Make science evolve into a One Health approach to improve health and security: A white paper. One Health Outlook 2: 1-32.

Pedersen NC, 2014. An update on feline infectious peritonitis: Virology and immunopathogenesis. Veterinary Journal 201: 123-132.

Peeri NC, et al., 2020. The SARS, MERS and novel coronavirus (COVID-19) epidemics, the newest and biggest global health threats: What lessons have we learned?. International Journal of Epidemiology 49: 717-726.

Tomas P, 2020. Coronavirus: Why you must act now." Politicians, community leaders and business leaders: What should you do and when.

Rahman MS, et al., 1999. Drying and food preservation." Handbook of Food Preservation. Marcel Dekker, New York, USA: pp: 173-216.

Raj VS, et al., 2013. Dipeptidyl peptidase 4 is a functional receptor for the emerging human coronavirus-EMC. Nature 495: 251-254.

Rasul G, 2016. Managing the food, water, and energy nexus for achieving the sustainable development goals in South Asia. Environmental Development 18: 14-25.

Robinson RK et al., 2020. Microbiology of fermented milks. Dairy microbiology handbook: The Microbiology of Milk and Milk Products $468.3^{\text {rd }}$ Edition.

Rosegrant MW et al., 2003. Global food security: Challenges and policies. Science 302: 1917-1919.

Salomonsson S, et al., 2003. Cellular basis of ectopic germinal center formation and autoantibody production in the target organ of patients with Sjögren's syndrome. Arthritis and Rheumatism 48: 3187-3201.

Samarin GN, et al., 2018. Optimization of microclimate parameters inside livestock buildings. Advances in Intelligent Systems and Computing, vol 866. Springer, Cham.

Semagn K, et al., 20o6. An overview of molecular marker methods for plants. African Journal of Biotechnology 5: 25 .

Shaner Willis W, 2019. Farming systems research and development: Guidelines for developing countries. Routledge $1^{\text {st }}$ Edition New York pages 434.

Shi J, et al., 2020. Susceptibility of ferrets, cats, dogs, and other domesticated animals to SARS-coronavirus 2. Science 368: 1016-1020.

Smith AC, et al., 2019. Telehealth for global emergencies: Implications for coronavirus disease 2019 (COVID19). Journal of Telemedicine and Telecare 26(5): 309313.

Subbarao G, et al., 2006. A bioluminescence assay to detect nitrification inhibitors released from plant roots: A case study with Brachiaria humidicola. Plant and Soil 288: 101-112.

Subbarao K, et al., 2006. Is there an ideal animal model for SARS? Trends in Microbiology 14: 299-303.

Jiumeng $S$, et al., 2020. COVID-19: Epidemiology, evolution, and cross-disciplinary perspectives. Trends in Molecular Medicine Trends in molecular medicine, 26: 483-495.

Tesso G, 2020. Review of the impact of COVID-19 on economic growth, unemployment and progress out of poverty in Ethiopia.

Thornton PK, 2010. Livestock production: Recent trends, future prospects. Philosophical Transactions of the Royal Society B: Biological Sciences 365: 2853-2867.

Tiwari RK, et al., 2020. Microglial TLR9: Plausible novel target for therapeutic regime against Glioblastoma multiforme. Cellular and Molecular Neurobiology 2020: 1-3.

Wang D, et al., 2020. Clinical characteristics of 138 hospitalized patients with 2019 novel coronavirusinfected pneumonia in Wuhan, China. Journal of the American Medical Association 323: 1061-1069.

$\mathrm{Wu}$ P, et al., 2020. Characteristics of ocular findings of patients with coronavirus disease 2019 (COVID-19) in Hubei Province, China. Journal of the American Medical Association Ophthalmology 138: 575-578.

Wurtzer S, et al., 2020. Time course quantitative detection of SARS-CoV-2 in Parisian wastewaters correlates with COVID-19 confirmed cases. MedRxiv 2020.04.12.20062679.

Xiong DH, et al., 2006. Robust and comprehensive analysis of 20 osteoporosis candidate genes by very high-density single-nucleotide polymorphism screen among 405 white nuclear families identified significant association and gene-gene interaction. Journal of Bone and Mineral Research 21: 1678-1695.

$\mathrm{Xu} \mathrm{X}$, et al., 2020. Evolution of the novel coronavirus from the ongoing Wuhan outbreak and modeling of its spike protein for risk of human transmission. Science China Life Sciences 63: 457-460.

$\mathrm{Xu} \mathrm{Y}$, et al., 2020. Enhancing genetic gain through genomic selection: From livestock to plants. Plant Communications 1: 100005.

Yang X, et al., 2020. Clinical course and outcomes of critically ill patients with SARS-CoV-2 pneumonia in Wuhan, China: A single-centered, retrospective, observational study. The Lancet Respiratory Medicine 8: $475-481$.

Zhang JJ, et al., 2020. Clinical characteristics of 140 patients infected with SARS-CoV-2 in Wuhan, China. Allergy 75: 1730-1741.

Zhou X et al., 2020. The role of telehealth in reducing the mental health burden from COVID-19. Telemedicine and e-Health 26: 377-379.

Zhou F, et al., 2020. Clinical course and risk factors for mortality of adult inpatients with COVID-19 in Wuhan, China: A retrospective cohort study. The Lancet 395: 1054-1062.

Zhou P, et al., 2020. A pneumonia outbreak associated with a new coronavirus of probable bat origin. Nature 579: 270-273. 